\section{CAPjoint, A Computer Software Package for Joint Inversion of Moderate Earthquake Source Parameters with Local and Teleseismic Waveforms}

\section{by Weiwen Chen, Sidao Ni, Hiroo Kanamori, Shengji Wei, Zhe Jia, and Lupei Zhu}

Online Material: CAPjoint software instructions.

\section{INTRODUCTION}

Accurate earthquake source parameters such as fault mechanism, depth, and moment magnitude are not only important in seismic-hazard assessment, but also are crucial to studies of earthquake rupture processes and seismotectonics. Although large earthquakes $\left(M_{\mathrm{w}} 7+\right)$ may cause substantial damage, they occur less frequently. In contrast, moderate earthquakes $\left(M_{\mathrm{w}} 5.0-6.5\right)$ occur with much higher frequency and may occur on faults not geologically identified. Some of the moderate earthquakes cause damage in densely populated communities, especially in developing countries (Baumbach et al., 1994; Hamzehloo, 2005). For example, the $2011 M_{\mathrm{w}} 5$ earthquake in Lorca, Spain (Pro et al., 2014), the $2012 M_{\mathrm{w}} 5.9$ Ferrara earthquake sequence in northern Italy (Malagnini et al., 2012), the $2010 M_{\mathrm{w}} 5$ Suining earthquake in Sichuang Province of China (Luo et al., 2011), and the 1998 $M_{\mathrm{w}} 5.7$ Zhangbei earthquake in Hebei Province of China (Li et al., 2008) all caused substantial economic loss and casualty. Compared with events larger than $M_{\mathrm{w}} 7$, rupture processes of these moderate events can be approximated as point sources, which are usually described with a centroid moment tensor (CMT) because the rupture duration is usually shorter than the period used in the waveform inversion.

Many algorithms and software packages have been developed to invert CMT parameters using seismic waveform data. For example, long-period teleseismic waveforms have been routinely used to determine source parameters, such as a $W$ phase solution, Global CMT catalog, and U.S. Geological Survey (USGS) fast moment tensor solutions (Dziewonski et al., 1981; Ekström et al., 2012). However, centroid depth is usually not well resolved in these long-period solutions. Centroid depth estimation is improved with teleseismic body-wave solutions (Chen and Molnar, 1983; Saikia, 2006), which are also routinely reported by National Earthquake Information Center (NEIC)/USGS for $M_{\mathrm{w}} 6+$ earthquakes. With a bootstrapping approach, Zhan et al. (2012) confirm that centroid depth and dip angle can be accurately resolved with inversion of teleseismic body-wave data when the earthquakes are recorded at many seismic stations (Zhan et al., 2012).

When moderate earthquake records are not clipped, local seismic waveform data can be used in modeling source parameters of moderate earthquakes; examples are the routine moment tensor solutions by Northern California Earthquake Center and Saint Louis University (Dreger and Helmberger, 1993; Dreger et al., 2000; Herrmann et al., 2011). To avoid the overweighting problem of surface wave in full-waveform inversion, a method called cut and paste (CAP) was developed, in which seismic waveforms are separated into body waves and surfaces waves (Zhao and Helmberger, 1994; Zhu and Helmberger, 1996). Several software packages were introduced based on all these different waveform inversion algorithms (Zwick et al., 1994; Ichinose et al., 1997; Saikia, 2006; Sokos and Zahradnik, 2008).

$M_{\mathrm{w}} 5.5+$ earthquakes are usually well recorded at both teleseismic and local distances. Intuitively, a combination of both teleseismic and local seismic waveforms provides more constraints on earthquake source parameters. Using inversion of local waveform data and forward modeling of teleseismic body waveforms, Wei et al. (2009) confirmed that an $M_{\mathrm{w}} 5.8$ earthquake in northern China occurred in the lower crust. Chen et al. (2012) developed a method of joint inversion with teleseismic and local seismic waveforms; they found that joint inversion improves either accuracy of centroid depth as compared with local waveform inversion only or accuracy of fault-plane parameters as compared with teleseismic waveform inversion only (Chen et al., 2012). The necessity for joint inversion of teleseismic and local waveforms is more obvious for studies of recent $M_{\mathrm{w}} 5$ events recorded by sparse networks and particularly earthquakes decades ago. For example, in the early 1990s, seismic network coverage was sparse, and a moderate earthquake was well recorded with only a few teleseismic and local stations. Inversion of only teleseismic or local seismic waveform data does not have enough data for good constraints on source parameters. Even for $M_{\mathrm{w}} 5$ earthquakes occurring in the present day, joint inversion is still necessary because seismic networks are very sparse in most regions of the world (except California, Japan, etc.) and earthquakes in these regions are usually recorded with only one or two stations. At the same time, only a few seismic stations are available with clear teleseismic body wave for inversion.

In this article, we presented a software package for source parameter inversion (moment magnitude, fault-plane parameters, and centroid depth) of moderate earthquakes, with local or teleseismic waveforms independently or for joint inversion with both datasets (the software package and the user's manual 

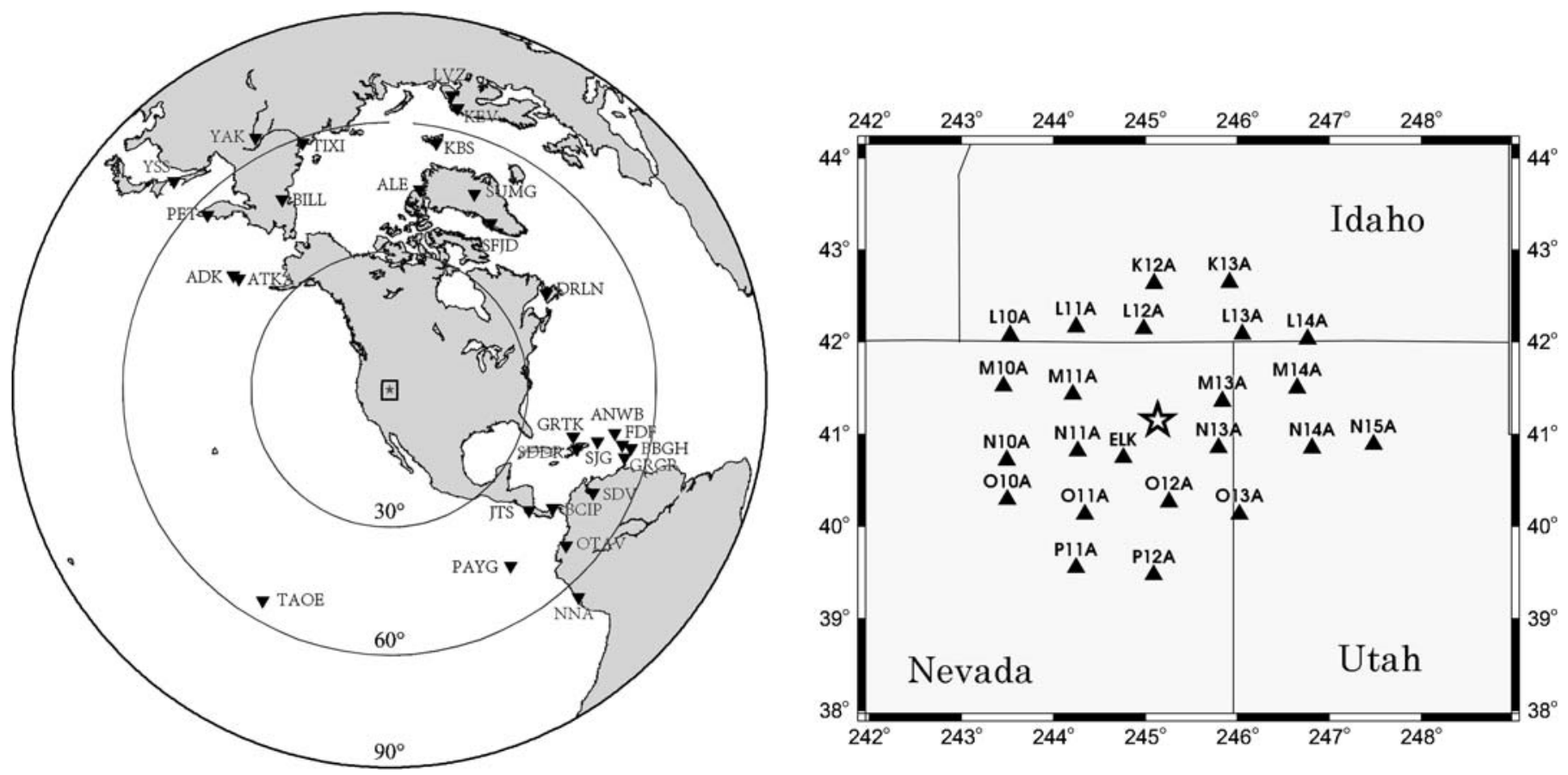

A Figure 1. The 2008 Wells, Nevada, earthquake (star) and the stations (triangles) recording the event. The distribution of teleseismic stations is shown on the left, and the local seismic network is shown on the right.

are available from http://staff.ustc.edu.cn/ sdni/literature/ capjoint; last accessed January 2015). As the software package involves segments of local waveforms or teleseismic body waves (in contrast to the whole waveforms as required by Global CMT methods), the earthquake source parameters can be inverted soon after an earthquake, thus providing rapid earthquake information for seismic-hazard mitigation purposes. The capability of the software package is demonstrated in a case study of the 2008 Wells earthquake (Nevada) source parameter inversion.

\section{THE JOINT INVERSION ALGORITHM WITH LOCAL AND TELESEISMIC WAVEFORM DATA}

Before source parameter inversion, Green's functions have to be computed for both local and teleseismic distances. For Green's function at local distances, the frequency-wavenumber integral method is adopted, and a 1D layered velocity model is required (Zhu and Rivera, 2002). For Green's function at teleseismic distances, the propagator matrix method with planewave approximation is used (Kikuchi and Kanamori, 1982), and different $1 \mathrm{D}$ velocity models can be used for source region and receiver (station) regions. Based on the teleseismic body wave subroutines from Kikuchi and Kanamori (1982), we implemented a code (TEL3) for computing teleseismic Green's functions for the same three basic fault geometries as those used by Zhu and Rivera (2002). To specify the 1D layered model, parameters such as number of layers, thickness, $P$-wave velocity, $S$-wave velocity, and density are required. The TEL3 code also requires mantle attenuation parameters for both teleseismic $P$ and $S H$ waves (denoted by $t_{P}^{*}$ and $t_{S}^{*}$, which are usually taken to be 1.0 and $4.0 \mathrm{~s}$, respectively). Usually the CRUST2.0 database is used to get $1 \mathrm{D}$ velocity models for computing Green's functions (Bassin, 2000).

A double-couple mechanism is assumed during source parameter inversion. Synthetic seismograms are computed with the following equation:

$u_{n}(x, t)=M_{p q} * G_{n p, q}$,

in which $u_{n}(x, t)$ is the observed ground motion (usually displacement or velocity) at a spatial location $x, G_{n p, q}$ is the spatial derivative of the Green's function at location $x$ and time $t$ due to an impulsive single force, and $M_{p q}$ is the moment tensor. The indices $p$ and $q$ refer to spatial coordinates (the Einstein summation rule is adopted; i.e., two identical indices means summation), and $n$ is the $n$th component of the spatial coordinate (Aki and Richards, 2002).

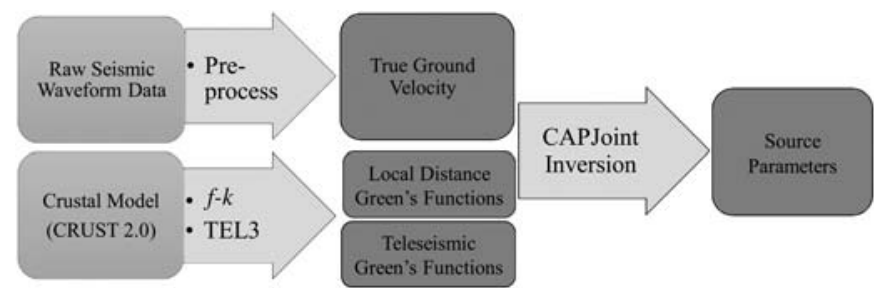

A Figure 2. Flowchart of the major modules of the CAPjoint software. Frequency-wavenumber integral method $(f-k)$ and teleseismic body-wave synthetic code (TEL3) identify two synthetic programs for computing local and teleseismic distance Green's functions, respectively. CRUST2.0 is the database of global crustal models from Bassin (2000). 
For double-couple seismic sources, equation (1) can be rewritten by weighted combination of Green's functions for three basic faults: a vertical strike-slip fault $(S S)$, a vertical dipslip fault $(D S)$, and a dip-slip fault with $45^{\circ}$ dip angle $(D D)$ (Herrmann and Wang, 1985).

$$
\begin{aligned}
u_{Z}= & (\sin 2 \vartheta \cos \lambda \sin \delta+0.5 \cos 2 \vartheta \sin \lambda \sin 2 \delta) \times S S_{Z} \\
& +(\cos \vartheta \cos \lambda \cos \delta-\sin \vartheta \sin \lambda \cos 2 \delta) \times D S_{Z} \\
& +0.5 \sin \lambda \sin 2 \delta \times D D_{Z} \\
u_{R}= & (\sin 2 \vartheta \cos \lambda \sin \delta+0.5 \cos 2 \vartheta \sin \lambda \sin 2 \delta) \times S S_{R} \\
& +(\cos \vartheta \cos \lambda \cos \delta-\sin \vartheta \sin \lambda \cos 2 \delta) \times D S_{R} \\
& +0.5 \sin \lambda \sin 2 \delta \times D D_{R} \\
u_{T}= & -(\sin \vartheta \cos \lambda \cos \delta+\cos \vartheta \sin \lambda \cos 2 \delta) \times D S_{T} \\
& +(\cos 2 \vartheta \cos \lambda \sin \delta-0.5 \sin 2 \vartheta \sin \lambda \sin 2 \delta) \times S S_{T}
\end{aligned}
$$

in which $Z, R$, and $T$ are vertical, radial, and tangential components, respectively; and $\vartheta, \lambda$, and $\delta$ represent the difference between source-station azimuth and the strike of the fault, slip rake, and dip angle, respectively.

After Green's functions are computed at both local and teleseismic distances, the CAP inversion tool is adopted for inversion (Zhao and Helmberger, 1994; Zhu and Helmberger, 1996). The CAP program partitions seismic waveforms into $P n l$ and surface wave parts and has the advantage of avoiding domination of large amplitude surface waves. Moreover, Pnl and surface waves are allowed to time shift differently to achieve the best correlation between observed and synthetic ground motion, and this may suppress errors due to inaccurate velocity structures. For local waveforms at each station, a total of five waveform segments are used: the radial and vertical components of the $P n l$ wave, the radial and vertical component of the Rayleigh wave, and the tangential component of the Love wave. For teleseismic waveforms of $P$ and $S H$ waves, only the vertical component of the $P$ wave and the tangential component of the $S H$ wave are used in the inversion.

The quality of the solution was determined by the fit between synthetic and observed waveforms, which was quantified through the sum of the L2 norm of misfit errors,

$$
\begin{aligned}
& e=\left[w_{P n l / \text { surface }} \times\left(r / r_{0 \text { loc }}\right)^{\varepsilon_{P n l}}\left\|u_{P n l}-s_{P n l}\right\|\right. \\
& \left.+\left(r / r_{0 \text { loc }}\right)^{\varepsilon_{\text {surface }}}\left\|u_{\text {surface }}-s_{\text {surface }}\right\|\right] \\
& +w_{\text {tel } / \text { loc }} \times\left[w_{P_{-} \text {tel } / S H_{-} \text {tel }} \times\left(r / r_{0 \text { tel }}\right){ }^{\varepsilon_{P_{-} \text {cel }}}\left\|u_{P_{-} \text {tel }}-s_{P_{-} \text {tel }}\right\|\right. \\
& \left.+\left(r / r_{0 \text { tel }}\right)^{\varepsilon_{S H_{-} \text {tel }}}\left\|u_{S H_{-} \text {tel }}-s_{S H_{-} \text {tel }}\right\|\right] \text {, }
\end{aligned}
$$

in which $r$ stands for epicentral distance, $r_{0}$ is the reference value for determine the relative weight at different epicentral distance, $\varepsilon$ is the exponential factor to increase the weight of smaller ground motion at larger distances, $u$ refers to recorded data, and $s$ is synthetic waveform. Indices loc or tel represent local or teleseismic waves, respectively, whereas $P n l$ and surface stand for local $P n l$ and surface waves. The weight $w_{\text {tel } / \text { loc }}$ is used to balance the contribution between local seismic data and teleseismic data, as local ground motion is substantially larger than teleseismic ones. The weight $w_{P_{-} \text {tel } / S H_{-} \text {tel }}$ is adopted to balance the amplitude difference between teleseismic $P$ and $S H$ waves, because teleseismic $S H$ waves have much higher amplitudes due to the double-couple nature of tectonic earthquakes.

The L2 norm is actually applied as the difference between aligned synthetic and observed seismograms; that is, the synthetic seismograms $f(t)$ are first aligned with observed seismograms $g(t)$ via cross correlation. The cross-correlation function is defined for a time window between $t_{1}$ and $t_{2}$ :

$C(t)=\frac{\int_{t_{1}}^{t_{2}} f(\tau) g(t+\tau) d \tau}{\left[\int_{t_{1}}^{t_{2}} f^{2}(\tau) d \tau \int_{t_{1}}^{t_{2}} g^{2}(\tau) d \tau\right]^{1 / 2}}$,

in which $u(t)$ and $s(t)$ represent data and synthetics, respectively, whereas $t$ refers to the relative time shift. The cross-correlation coefficient between the synthetic and observed seismograms is then defined at the maximum of $C(t)$. The time-window boundary $t_{1}$ and $t_{2}$ can be theoretically derived using arrival-time computing tools (e.g., TauP) from the input velocity models and can also be specified manually (Crotwell et al., 1999).

\section{SAMPLE INVERSION FOR THE $2008 M_{w} 6$ EARTHQUAKE IN WELLS, NEVADA}

On 21 February 2008, an $M_{\mathrm{w}} 6.0$ earthquake occurred near the community of Wells, Nevada. It occurred in the region covered

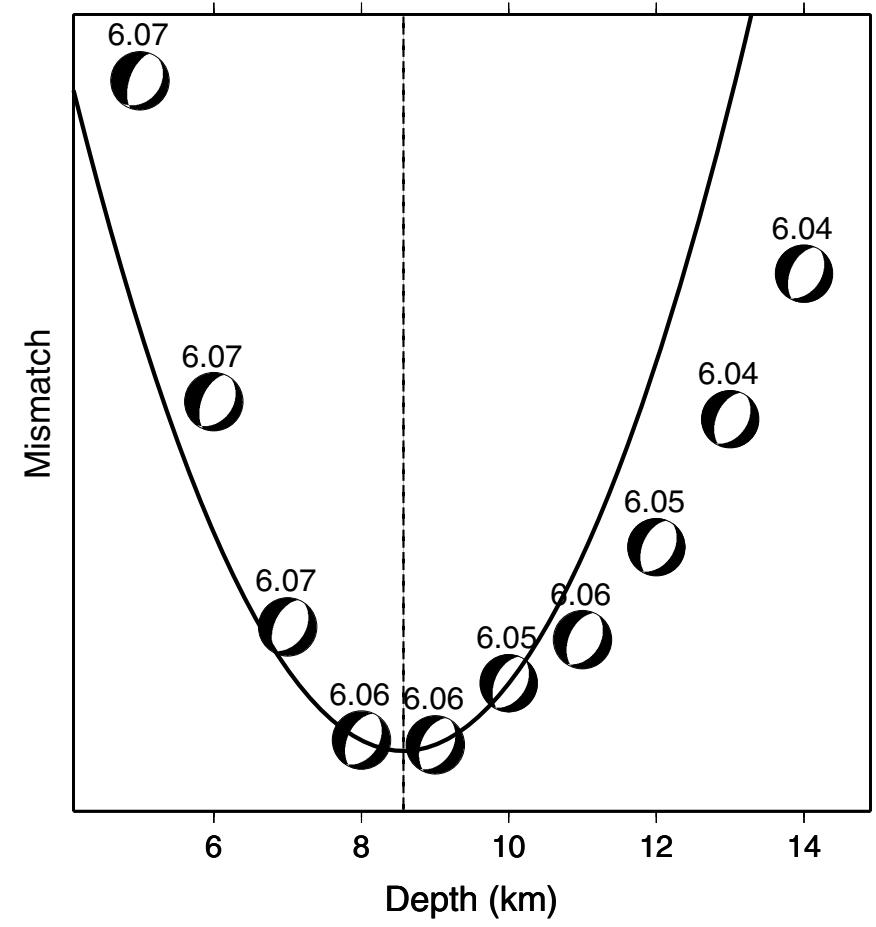

A Figure 3. Waveform mismatch versus centroid depth. Numbers above the beach ball indicate moment magnitude $\left(M_{\mathrm{w}}\right)$ for each depth. 


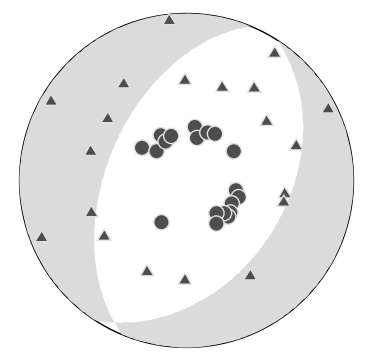

Model_depth nevada_9 $M_{\mathrm{w}} 6.06$ RMS 5.260e+01

FM1 33/40/-82 FM2 202/50/-96

$-\mathrm{C} 0.02 / 0.16 / 0.02 / 0.1$

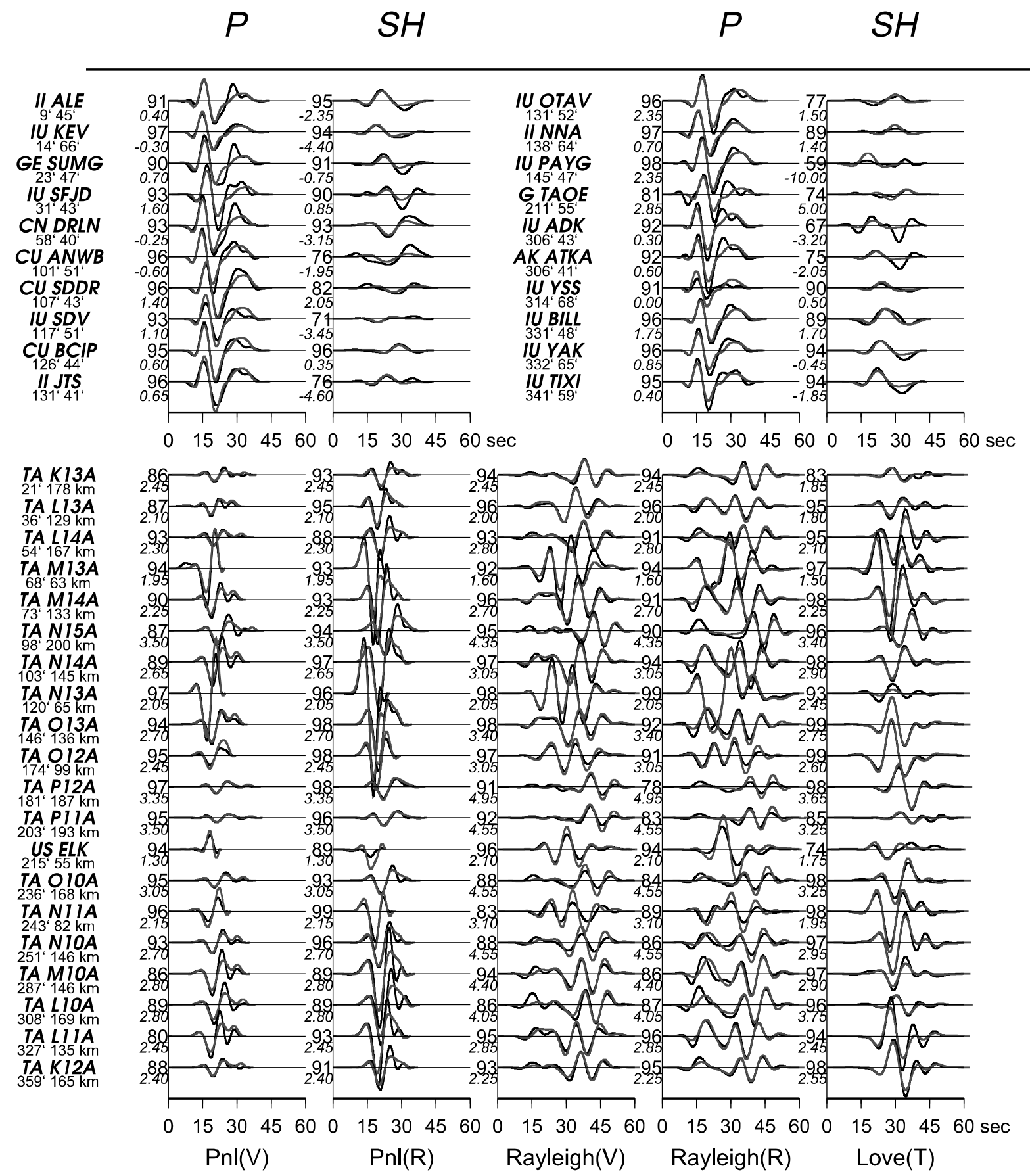

$\Delta$ Figure 4. CAPjoint inversion for the 2008 Nevada earthquake. The black lines are observed data, and the gray lines are synthetics. Numbers to the left of the seismograms are time shifts (lower, italicized numbers) and cross-correlation coefficient in percent (upper numbers). Positive time shifts indicate that synthetic waveforms are delayed. The triangles on the focal sphere represent the local stations, whereas and the circles are teleseismic stations. 


\begin{tabular}{|lccc|}
\hline \multicolumn{4}{|c|}{$\begin{array}{c}\text { Table 1. } \\
\text { Source Parameters Derived from This Research and Other } \\
\text { Agencies }\end{array}$} \\
\hline \multicolumn{1}{|c}{ Source } & $\begin{array}{c}\text { Moment } \\
\text { Magnitude }\end{array}$ & $\begin{array}{c}\text { Depth } \\
\text { (km) }\end{array}$ & $\begin{array}{c}\text { Plane I } \\
\text { (Strike/Dip/ } \\
\text { Rake) ( }{ }^{\circ} \text { ) }\end{array}$ \\
\hline $\begin{array}{l}\text { U.S. Geological } \\
\text { Survey (USGS) }\end{array}$ & 6.0 & 10 & $9 / 58 /-114$ \\
$\begin{array}{l}\text { centroid moment } \\
\text { tensor (CMT) }\end{array}$ & & & \\
$\begin{array}{l}\text { USGS body-wave } \\
\text { moment tensor (MT) }\end{array}$ & 5.8 & 7 & $19 / 33 /-96$ \\
Dreger et al. (2008) & 5.95 & $7-9$ & $34 / 40 /-83$ \\
Global CMT & 6.0 & 14.1 & $36 / 44 /-81$ \\
CAPjoint MT & 6.06 & 8.6 & $33 / 40 /-82$ \\
\hline
\end{tabular}

by the dense USArray network, thus abundant local seismic waveforms are available for inversion, along with high-quality body-wave data at teleseismic distances. We requested both local $\left(0^{\circ}-5^{\circ}\right)$ and teleseismic $\left(30^{\circ}-90^{\circ}\right)$ waveforms from fast archive recovery method system of the Incorporated Research Institutions for Seismology. For this event, we collected high signal-to-noise ratio three-component waveform data from 23 local and 35 teleseismic stations (Fig. 1). We preprocessed waveform data by removing the linear trend and deconvolving the instrument response. After true amplitude, the three-component ground motion was recovered, they were rotated along the great circle path to get radial and tangential components. The preprocessed ground-motion data were then stored in a specified
Table 2.

Source Parameters Inverted for the Five Cases of 20 Local Stations and/or 20 Teleseismic Stations

\begin{tabular}{|lcrl|}
\hline Inversion Case & $\begin{array}{c}\text { Moment } \\
\text { Magnitude }\end{array}$ & $\begin{array}{c}\text { Depth } \\
(\mathbf{k m})\end{array}$ & $\begin{array}{c}\text { Plane I (Strike/ } \\
\text { Dip/Rake) }\left(^{\circ}\right)\end{array}$ \\
\hline 20 tel+20 local & 6.06 & 8.6 & $33 / 40 /-82$ \\
20 local & 6.05 & 8.4 & $33 / 39 /-82$ \\
20 tel_P & 6.11 & 7.6 & $15 / 40 /-84$ \\
20 tel_SH & 6.10 & 10.7 & $35 / 40 /-84$ \\
20 tel_P+SH & 6.08 & 11.0 & $31 / 41 /-82$ \\
\hline
\end{tabular}

directory as required by the CAPjoint software (see manual for details).

After data preprocessing was completed, the Green's functions were computed by the frequency-wavenumber integral method code for local stations and the TEL3 code for teleseismic stations. In the CAP inversion method, centroid depth is found via grid searching. Therefore, Green's functions were computed for the depth at each grid. For each given depth, the typical central processing unit (CPU) time on a Linux 1686 work station (Intel Xeon CPU $2.40 \mathrm{GHz}$ ) is about $50 \mathrm{~s}$ for Green's functions computation at 20 teleseismic stations and about $100 \mathrm{~s}$ for Green's functions computation at 20 local stations (grid steps of the moment magnitude, depth, and strike/dip/rake are 0.1 , $1 \mathrm{~km}, 5^{\circ}$, respectively).

Once the Green's function calculation is completed, the best-fit focal mechanism and moment magnitude $\left(M_{\mathrm{w}}\right)$ can be found with the joint inversion code CAPjoint in a gridsearching approach. The grid search is performed in two steps:
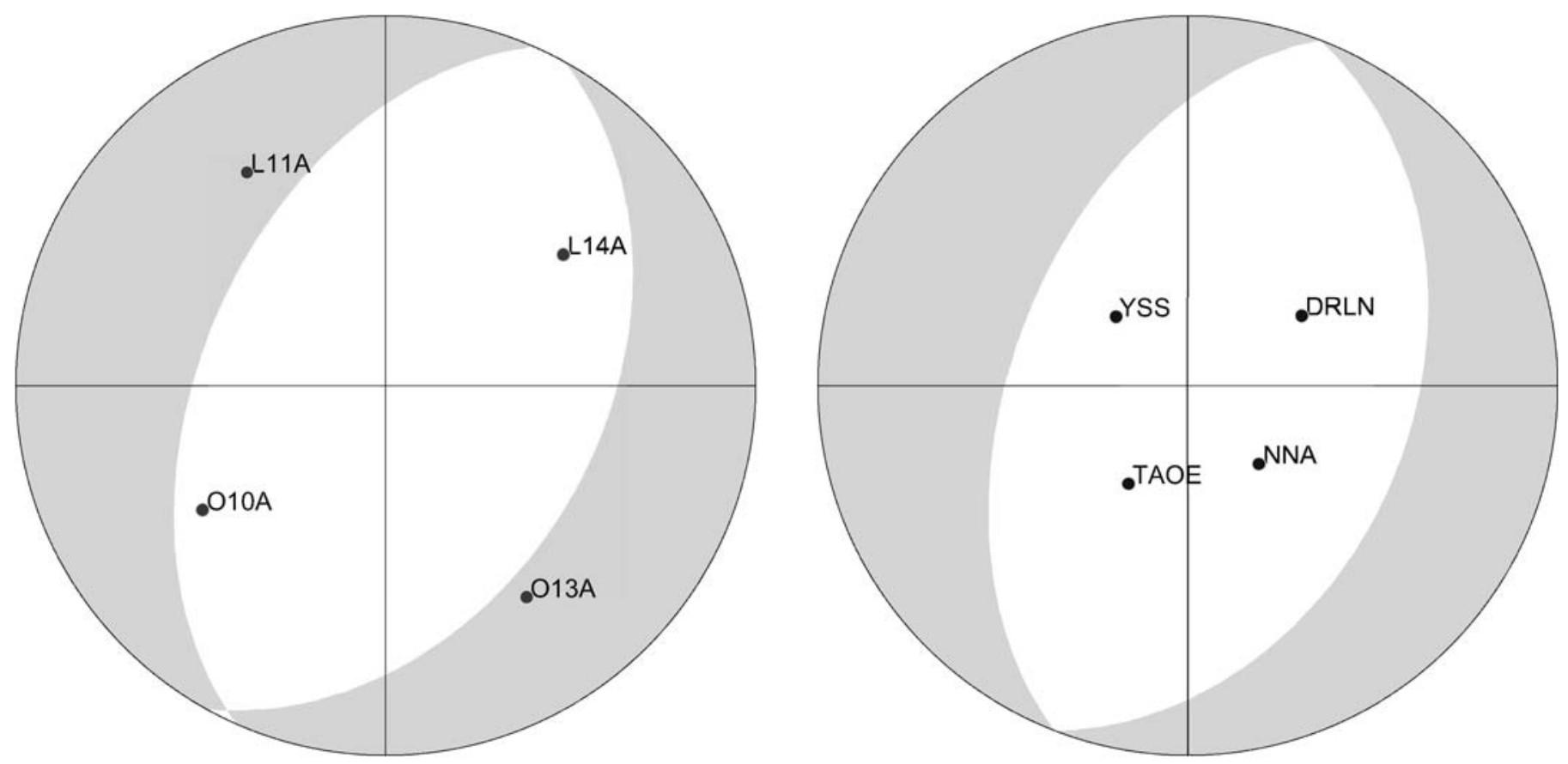

A Figure 5. (Left) Local and (right) teleseismic stations projected on the focal sphere for the case of four local stations and four teleseismic stations (see Table 3). 


\section{Table 3.}

\begin{tabular}{|c|c|c|c|}
\hline \multicolumn{4}{|c|}{$\begin{array}{c}\text { Source Parameters Inverted for the Five Cases of Four Local } \\
\text { Stations and/or Four Teleseismic Stations and the Case of } \\
\text { One Local Stations with/without the Joint Inversion by } \\
\text { Four Teleseismic Stations }\end{array}$} \\
\hline $\begin{array}{c}\text { Inversion } \\
\text { Case }\end{array}$ & $\begin{array}{c}\text { Moment } \\
\text { Magnitude }\end{array}$ & $\begin{array}{l}\text { Depth } \\
\text { (km) }\end{array}$ & $\begin{array}{c}\text { Plane I (Strike/ } \\
\text { Dip/Rake) }\left({ }^{\circ}\right)\end{array}$ \\
\hline $\begin{array}{l}\text { Four tel }+ \\
\text { four local }\end{array}$ & 6.05 & 8.2 & $31 / 41 /-84$ \\
\hline Four local & 6.05 & 8.1 & $29 / 41 /-86$ \\
\hline Four tel_$P$ & 6.09 & 11.7 & $138 / 52 /-56$ \\
\hline Four tel_SH & 6.14 & 9.9 & $31 / 42 /-90$ \\
\hline $\begin{array}{c}\text { Four tel_P+ } \\
\qquad H\end{array}$ & 6.05 & 11.9 & 21/39/-90 \\
\hline $\begin{array}{c}\text { Four tel + one } \\
\text { local }\end{array}$ & 6.06 & 8.3 & $34 / 39 /-86$ \\
\hline One local & 5.97 & 11.3 & $15 / 43 /-107$ \\
\hline
\end{tabular}

first with a coarse grid search (default $5^{\circ}$ interval for strike, dip, and rake angles), then with a refined grid search when a global minimum is found during the first stage. A perl script, cap3.pl, is implemented to facilitate the joint inversion process. The script prompts for input of a variety of control parameters, including data type (displacement or velocity), the source time function, initial moment magnitude, grid-search range and step, time-window length, and weight between local or teleseismic stations, as well as $P$ or $S H$ waves.

For the sample study of the Nevada earthquake, the distance scaling powers is 1.0 for body waves and 0.5 for surface waves. The time window for waveform segment is $60 \mathrm{~s}$. The sampling rate of data and synthetic waveforms is 20 per second, and the input source time duration is $5.0 \mathrm{~s}$. The maximum time shift allowed in inversion is $5.0 \mathrm{~s}$ for $P$ waves and $10.0 \mathrm{~s}$ for surface and $S H$ waves. Both data and the Green's functions were converted to ground velocity and band-pass filtered with a four-pole Butterworth filter between 0.02 and $0.16 \mathrm{~Hz}$ for $P$-wave components and $0.02-0.1 \mathrm{~Hz}$ for local surface wave and teleseismic $S H$ waveforms. Figure 2 shows the major function modules of the software package.

The passbands are chosen to account for background noise and the inaccuracy of $1 \mathrm{D}$ waveform modeling. First, because of the strong secondary microseism (around 5-6s), the higher end of the passband is usually chosen to be less than $0.16 \mathrm{~Hz}$ (or $6 \mathrm{~s}$ ). Usually the surface wave is more affected by $3 \mathrm{D}$ heterogeneities, thus $0.1 \mathrm{~Hz}$ is chosen for surface waves, whereas $0.16 \mathrm{~Hz}$ is chosen for body waves. For regions with very strong lateral variation (e.g., near the edges of the Tibetan plateau or near the ocean-continent boundary), a lower frequency is needed to average out $3 \mathrm{D}$ heterogeneity so that the $1 \mathrm{D}$ velocity model is more applicable.

For a typical moderate event $\left(M_{\mathrm{w}} 5.5-6.5\right)$, recommendation values for beginners are $0.01-0.15 \mathrm{~Hz}$ for $P$ waves and $0.01-0.1 \mathrm{~Hz}$ for surface waves and $S H$ waves. Source time duration can be set as $5 \mathrm{~s}$ for the first run to estimate moment magnitude, and then the duration is determined from earthquake scaling laws (Somerville et al., 1999). The time windows of teleseismic $P$ and $S H$ should be long enough to include the depth phases when the event is too deep.

\section{RESULTS AND DISCUSSION}

Because local and teleseismic waves sample different parts of the focal sphere, they have different sensitivity for the faultplane parameters. For example, almost all teleseismic $P$ waves show negative polarity for this high-angle normal-faulting earthquake, whereas local $P$ waves show alternating polarity for different station azimuths. When local seismic stations or teleseismic stations are sparse, single dataset of local or teleseismic data only provide limited constraints on earthquake source parameters, and joint inversion is needed to provide tighter constraints on all the parameters.

To further test the robustness of the joint inversion, we ran CAPjoint for the cases of (1) 20 local stations and 20 teleseismic stations, (2) only 20 local stations, (3) only 20 teleseismic stations with $P$ waves, (4) only 20 teleseismic stations with $S H$ waves, and (5) only teleseismic stations with both $P$ and $S H$ waves. After the tests with 20 stations are done, we do inversions with only four local or/and teleseismic stations.

For case 1, in which both local and teleseismic stations are involved in joint inversion, we obtained the source parameters as follows: centroid depthis $8.6 \mathrm{~km}$ (Fig. 3); nodal plane 1 has strike $33^{\circ}$, dip $40^{\circ}$, and rake $-82^{\circ}$; nodal plane 2 has strike $202^{\circ}$, dip $50^{\circ}$, and rake $-96^{\circ}$, and $M_{\mathrm{w}}$ is 6.06 (Fig. 4). Here, we used a quadratic fit to estimate the optimal depth, and the precision of centroid depth can be achieved beyond the depth search grid.

We compared the results with solutions from NEIC, the Global CMT, and other agencies (Table 1). NEIC and Global CMT use very-long-period full waveforms fit to invert the source parameters, whereas USGS body-wave inversion uses only body waves. Results given by Minson and Dreger (2008) are based on a full moment tensor inversion method applied to long-period waveforms at local distances. Our fault-plane solution and moment magnitude are close to the solution by Global CMT and by Dreger et al. (2008). The centroid depth is close to the USGS body-wave solution and CMT solution, as well as the result from Dreger $e t$ al. It seems the strike of faultplane I from the USGS CMT is substantially smaller than that from Global CMT. Relocated aftershocks and Interferometric Synthetic Aperture Radar studies confirmed the ruptured faultplane strikes $\mathrm{N} 35-40^{\circ} \mathrm{E}$ with a dip around $45^{\circ}-50^{\circ}$ (Smith et al., 2011; Bell et al., 2012). Overall, the results from seismology and geodesy are consistent.

For cases 2-4, proper source parameters can be obtained from either 20 local stations or 20 teleseismic $P+S H$ waveforms. However, if only teleseismic $P$ waves are used for inversion (which is quite common in teleseismic inversion studies), some of the parameters (especially the fault strike) are significantly different. This is due to the fact that teleseismic $P$ waves sample only the dilatational quadrant of the focal sphere for a 


\section{Model_depth nevada_8 $M_{\mathrm{w}} 6.06$ RMS $5.604 \mathrm{e}+00$ FM1 34/39/-86 FM2 208/51/-93 \\ $-\mathrm{C} 0.02 / 0.16 / 0.02 / 0.1$}

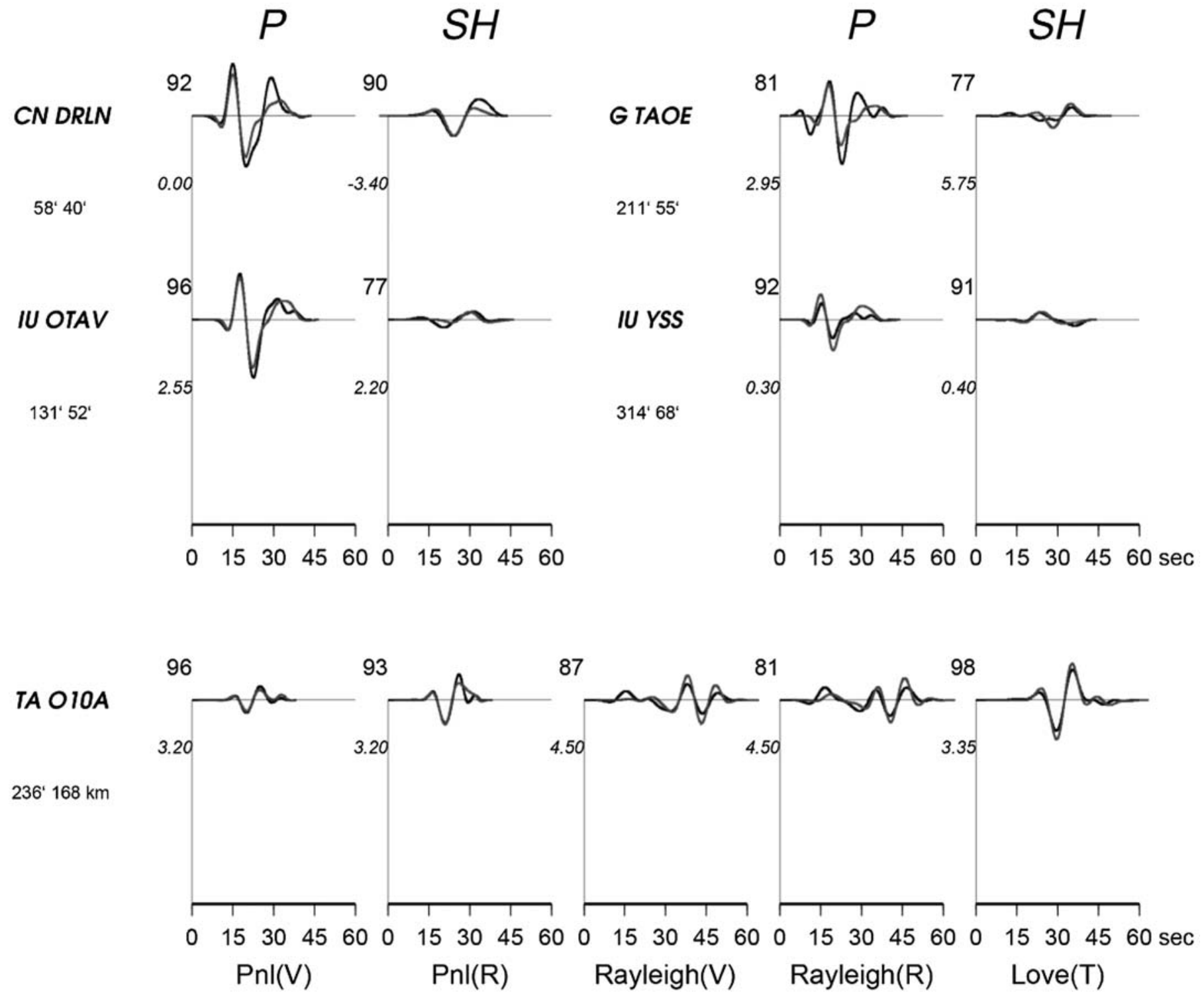

A Figure 6. CAPjoint modeling for the 2008 Nevada earthquake with four teleseismic stations and one local station. Refer to Figure 4 for a detailed description. 


\begin{tabular}{|llccl|}
\hline \multicolumn{5}{c}{ Comparison between Results from CAPjoint Inversions and from Global CMT } \\
\hline Event ID and Location & Catalog & Moment Magnitude & Depth (km) & Plane I (Strike/Dip/Rake) $\left(^{\circ}\right)$ \\
\hline $011098 A$ & CAPjoint & 5.88 & 5.0 & $194 / 42 / 132$ \\
Northeastern China & Global CMT & 5.7 & 15.0 & $207 / 54 / 135$ \\
201003040018A & CAPjoint & 6.17 & 21.0 & $317 / 36 / 52$ \\
Taiwan & Global CMT & 6.3 & 29.1 & $313 / 30 / 45$ \\
201111060353A & CAPjoint & 5.64 & 4.9 & $324 / 81 /-170$ \\
Oklahoma & Global CMT & 5.7 & 12.0 & $324 / 88 /-178$ \\
201405051108A & CAPjoint & 6.26 & 5.5 & $248 / 82 / 2$ \\
Thailand & Global CMT & 6.2 & 12.0 & $338 / 85 / 178$ \\
\hline
\end{tabular}

high-angle normal-fault earthquake. For such dip-slip events, $\mathrm{SH}$ waves are needed to resolve strike more accurately.

Then, we test the cases of many fewer local and teleseismic stations. We assume that only four local stations and four teleseismic stations are available and again perform similar five cases as indicated in Table 2. The four local stations and four teleseismic stations are chosen to be with good azimuth coverage so as to improve the accuracy of the earthquake source parameter estimate (Fig. 5). Even with many fewer stations, local stations can still provide reliable source parameters. CAP inversion with only two local stations can resolve source parameters quite well when local velocity structure is well known and station azimuth coverage is adequate (Tan, 2006). Similarly, with only four teleseismic stations, reasonable dip and rake can still be determined if the station azimuth coverage is good, but strike estimate is with noticeable error when only teleseismic $P$ waves are used in the inversion. The joint inversion with four local and four teleseis- mic stations yields a very similar solution to that with 20 local and 20 teleseismic stations.

As modern seismic network coverage is still very sparse for most regions of the world, many earthquakes are recorded only with one local station, so we test the case of only one local station and four teleseismic stations (Table 3). Understandably, CAP inversion with one local station does not provide reliable source parameters, and joint inversion substantially improves the solution accuracy. Inclusion of data from one local station also improves the estimate of strike when only four teleseismic stations are used (strike is $34^{\circ}$ with joint inversion and $21^{\circ}$ with only teleseismic data). See Figure 6 for more detailed information of joint inversion with one local station and four teleseismic stations.

We applied the CAPjoint method to five other events around the world and compared the solutions with the results from Global CMT (Table 4). Overall, the parameters agree
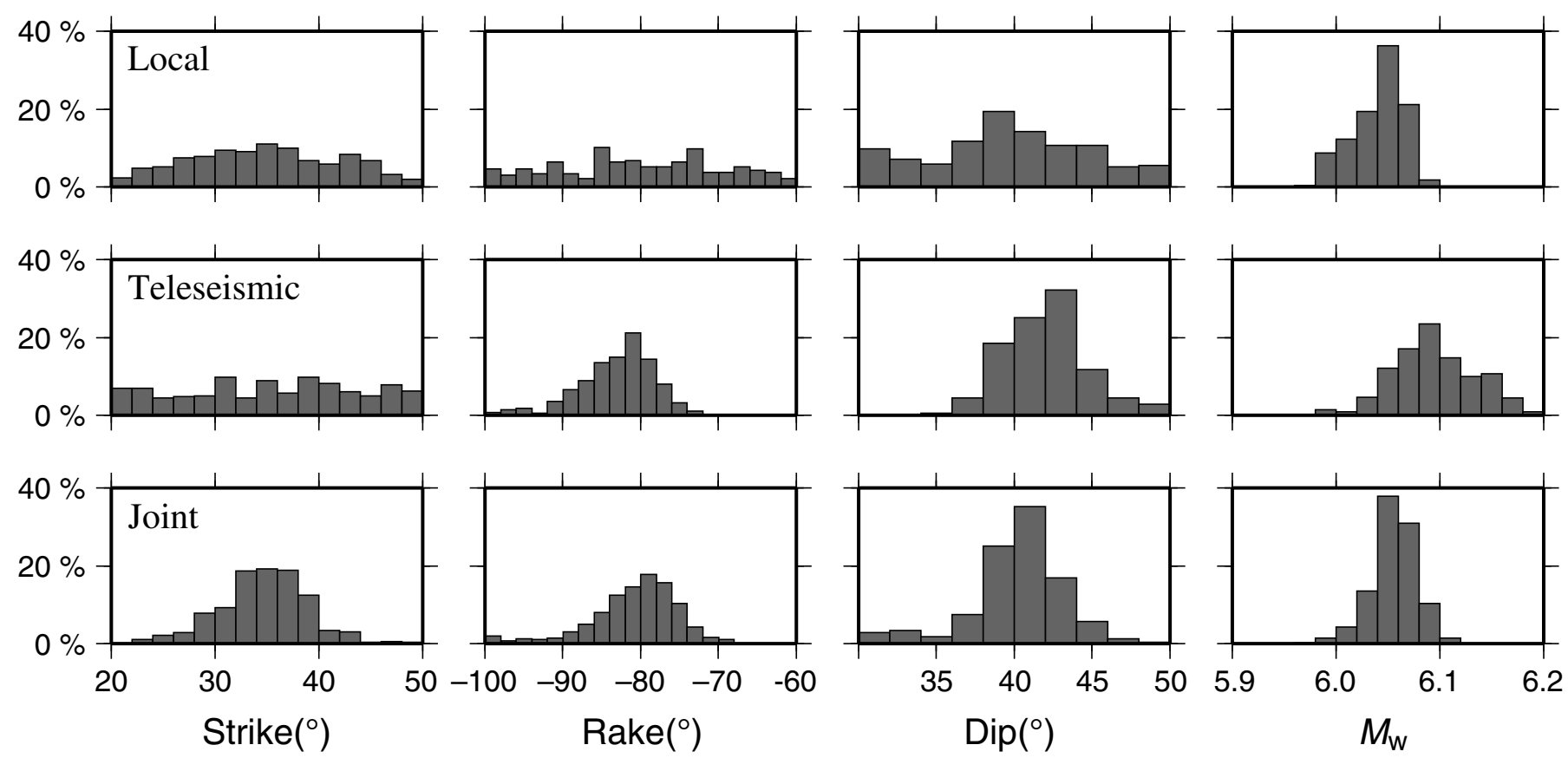

A Figure 7. Bootstrapping tests with random choices of stations from different datasets. (Top) Four random local stations, (middle) four random teleseismic stations, and (bottom) joint inversion with four local and four teleseismic stations. 
Table 5.

Inversion Results under Different Weighting or P-Wave Band-Pass Parameters (Passband Surface and SH Waves are Half of $P$-Wave Filter Band)

\begin{tabular}{|c|c|c|c|}
\hline Inversion Case & Moment Magnitude & Depth (km) & Plane I (Strike/Dip/Rake) $\left(^{\circ}\right)$ \\
\hline Four local & 6.05 & 8.1 & $29 / 41 /-86$ \\
\hline Four teleseismic & 6.05 & 11.9 & $21 / 39 /-90$ \\
\hline Joint weight tel/loc $1 / 1^{*}$ & 6.05 & 8.2 & $31 / 41 /-84$ \\
\hline Joint weight tel/loc $5 / 1^{*}$ & 6.06 & 10.6 & $26 / 39 /-91$ \\
\hline Joint weight tel/loc $1 / 5^{*}$ & 6.05 & 8.3 & $29 / 39 /-86$ \\
\hline Passband: $0.02-0.15 \mathrm{~Hz}$ & 6.05 & 8.7 & $31 / 39 /-84$ \\
\hline Passband: $0.02 \sim 0.10 \mathrm{~Hz}$ & 6.05 & 8.2 & $31 / 41 /-84$ \\
\hline Passband: $0.01-0.08 \mathrm{~Hz}$ & 6.05 & 8.2 & $29 / 40 /-81$ \\
\hline Passband: $0.01-0.05 \mathrm{~Hz}$ & 5.99 & 14.3 & $28 / 36 /-74$ \\
\hline
\end{tabular}

with each other quite well except for the centroid depth. The depth given by Global CMT is considered to be less reliable, especially for shallow events (Weston et al., 2011).

Uncertainties of results are essential in the evaluation of the inversion quality. Bootstrapping methods have been adopted in assessing uncertainties of earthquake source inversion (Zhan et al., 2012), so we also perform three bootstrapping tests in the CAPjoint inversions: first with four random local stations; then with four random teleseismic stations; and, in the last test, a joint inversion with four local and four teleseismic stations. The source parameter inversion results are displayed in Figure 7. For the local-data-only inversion, the rake and dip results are much scattered, and the strike is also not well resolved from the teleseismic-data-only inversion. With joint inversion, both the fault-plane parameters (dip, rake, and strike) and moment magnitude are better resolved, as shown by the more compact distribution.

Furthermore, the effects of weighting and band-pass filter choices on inversion are tested, and the results are listed in Table 5. Adding more weight to either local or teleseismic data makes the inverted source parameters closer to the result from the respective single dataset, but the results are still stable. Meanwhile, using different band-pass filter choices does not have a strong effect on the inversion in most cases. However, the band-pass filter should not be too long period; otherwise the centroid depth might not be well resolved, because depth phases in body waves are less prominent in long period.

\section{CONCLUSION}

We developed a new procedure (CAPjoint) to invert both local and teleseismic waveform data for source parameters of moderate earthquakes and then applied the algorithm to source parameter inversion of the 2008 Nevada $M_{\mathrm{w}} 6.0$ earthquake. We compared our results with moment tensor solutions from other agencies and found they are consistent. A series of tests on the number of stations used in the inversion suggests that joint inversion with inclusion of even one local station may improve the source parameter inverted from only teleseismic data.

The CAPjoint software package assumes a 1D layered velocity models for full-waveform modeling at both local and teleseismic distances. The package can be ported to $3 \mathrm{D}$ velocity models using Green's functions for 3D cases (Liu et al., 2004); however, for most parts of the world, reliable 3D velocity models are not available yet, and local 1D models (such as CRUST2.0) can be used instead (Bassin, 2000). The partitioned waveform inversion approach of CAP is less sensitive to inaccuracy of velocity models (Zhao and Helmberger, 1994).

This algorithm is recommended for studying moderate $\left(M_{\mathrm{w}}\right.$ 5.0-6.5) events, which can be recorded on global and local seismic networks but are not too large to invalidate the point-source assumption and to clip local seismic records. It is hoped that more reliable source parameters can be obtained with this new code package. $\mathbf{<}$

\section{ACKNOWLEDGMENTS}

Seismic waveform data were requested from Incorporated Research Institutions for Seismology-Data Management Center. This study is supported by Chinese Academy of Sciences (CAS) fund KZCX2-EW-121, 973 Program 2014CB845901, and National Science Foundation of China (NSFC) 41274069.

\section{REFERENCES}

Aki, K., and P. G. Richards (2002). Quantitative Seismology, Second Ed., University Science Books, Sausilito, California, ISBN 0-935702-96-2.

Bassin, C. (2000). The current limits of resolution for surface wave tomography in North America, Eos Trans. AGU 81, F897.

Baumbach, M., H. Grosser, H. Schmidt, A. Paulat, A. Rietbrock, C. V. R. Rao, P. S. Raju, D. Sarkar, and I. Mohan (1994). Study of foreshocks and aftershocks of the intraplate Latur earthquake of September 30, 1993, India, Latur Earthq. 35, 33-63.

Bell, J. W., F. Amelung, and C. D. Henry (2012). InSAR analysis of the 2008 Reno-Mogul earthquake swarm: Evidence for westward migration of Walker Lane style dextral faulting, Geophys. Res. Lett. 39, no. 18, L18306, doi: 10.1029/2012GL052795. 
Chen, W. P., and P. Molnar (1983). Focal depths of intracontinental and intraplate earthquakes and their implications for the thermal and mechanical properties of the lithosphere, J. Geophys. Res. 88, no. B5, 4183-4214.

Chen, W.-W., S.-D. Ni, Z.-J. Wang, X.-F. Zeng, and S.-J. Wei (2012). Joint inversion with both local and teleseismic waveforms for source parameters of the 2010 Kaohsiung earthquake, Chin. J. Geophys. 55, no. 7, 2319-2328.

Crotwell, H. P., T. J. Owens, and J. Ritsema (1999). The TauP toolkit: Flexible seismic travel-time and ray-path utilities, Seismol. Res. Lett. 70, no. 2, 154-160.

Dreger, D. S., and D. V. Helmberger (1993). Determination of source parameters at regional distances with three-component sparse network data, J. Geophys. Res. 98, no. B5, 8107-8125.

Dreger, D. S., S. Ford, and I. Ryder (2008). Finite-source study of the February 21, $2008 M_{\mathrm{w}} 6.0 \mathrm{Wells,} \mathrm{Nevada,} \mathrm{earthquake,} \mathrm{paper} \mathrm{presented} \mathrm{at}$ AGU Fall Meeting Abstracts S41D-07, San Francisco, California.

Dreger, D. S., H. Tkalčić, and M. Johnston (2000). Dilational processes accompanying earthquakes in the Long Valley Caldera, Science 288, no. $5463,122$.

Dziewonski, A., T. A. Chou, and J. Woodhouse (1981). Determination of earthquake source parameters from waveform data for studies of global and regional seismicity, J. Geophys. Res. 86, no. B4, 28252852.

Ekström, G., M. Nettles, and A. M. Dziewoński (2012). The Global CMT project 2004-2010: Centroid-moment tensors for 13,017 earthquakes, Phys. Earth Planet. In. 200/201, 1-9.

Hamzehloo, H. (2005). Determination of causative fault parameters for some recent Iranian earthquakes using near field $S H$-wave data, $J$. Asian Earth Sci. 25, no. 4, 621-628.

Herrmann, R. B., and C. Y. Wang (1985). A comparison of synthetic seismograms, Bull. Seismol. Soc. Am. 75, no. 1, 41-56.

Herrmann, R. B., L. Malagnini, and I. Munafò (2011). Regional moment tensors of the 2009 L'Aquila earthquake sequence, Bull. Seismol. Soc. Am. 101, no. 3, 975-993.

Ichinose, G. A., K. D. Smith, and J. G. Anderson (1997). Source parameters of the 15 November 1995 Border Town, Nevada, earthquake sequence, Bull. Seismol. Soc. Am. 87, no. 3, 652.

Kikuchi, M., and H. Kanamori (1982). Inversion of complex body waves, Bull. Seismol. Soc. Am. 72, no. 2, 491-506.

Li, Z., W. Feng, Z. Xu, P. Cross, and J. Zhang (2008). The $1998 M_{\mathrm{w}} 5.7$ Zhangbei-Shangyi (China) earthquake revisited: A buried thrust fault revealed with interferometric synthetic aperture radar, Geochem. Geophys. Geosys. 9, no. 4, doi: 10.1029/2007GC001910.

Liu, Q., J. Polet, D. Komatitsch, and J. Tromp (2004). Spectral-element moment tensor inversions for earthquakes in southern California, Bull. Seismol. Soc. Am. 94, no. 5, 1748-1761.

Luo, Y., S. Ni, X. Zeng, J. Xie, Y. Chen, and F. Long (2011). The M 5.0 Suining-Tongnan (China) earthquake of 31 January 2010: A destructive earthquake occurring in sedimentary cover, Chin. Sci. Bull. 56, no. 6, 521-525.

Malagnini, L., R. B. Herrmann, I. Munafò, M. Buttinelli, M. Anselmi, A. Akinci, and E. Boschi (2012). The 2012 Ferrara seismic sequence: Regional crustal structure, earthquake sources, and seismic hazard, Geophys. Res. Lett. 39, no. 19, doi: 10.1029/2012GL053214.

Minson, S. E., and D. S. Dreger (2008). Stable inversions for complete moment tensors, Geophys. J. Int. 174, no. 2, 585-592.

Pro, C., E. Buforn, S. Cesca, C. S. de Galdeano, and A. Udías (2014). Rupture process of the Lorca (southeast Spain) 11 May 2011 $\left(\mathrm{M}_{\mathrm{w}}=5.1\right)$ earthquake, J. Seismol. 18, no. 3, 481-495.

Saikia, C. K. (2006). Modeling of the 21 May 1997 Jabalpur earthquake in central India: Source parameters and regional path calibration, Bull. Seismol. Soc. Am. 96, no. 4A, 1396.

Smith, K., J. Pechmann, M. Meremonte, and K. Pankow (2011). Preliminary analysis of the $M_{\mathrm{w}} 6.0$ Wells, Nevada, earthquake sequence, Nevada Bureau of Mines and Geol. Spec. Publ. 36, $127-145$.
Sokos, E. N., and J. Zahradnik (2008). ISOLA a Fortran code and a MATLAB GUI to perform multiple-point source inversion of seismic data, Comput. Geosci. 34, no. 8, 967-977.

Somerville, P., K. Irikura, R. Graves, S. Sawada, D. Wald, N. Abrahamson, Y. Iwasaki, T. Kagawa, N. Smith, and A. Kowada (1999). Characterizing crustal earthquake slip models for the prediction of strong ground motion, Seismol. Res. Lett. 70, no. 1, 59-80.

Tan, Y. (2006). Broadband waveform modeling over a dense seismic network, Ph.D. Dissertation, California Institute of Technology, Pasadena, California.

Wei, S.-J., S.-D. Ni, J.-J. Chong, Y. Zheng, and Y. Chong (2009). The 16 August 2003 Chifeng earthquake: Is it a lower crust earthquake, Chin. J. Geophys. 52, 111-119.

Weston, J., A. Ferreira, and G. Funning (2011). Global compilation of interferometric synthetic aperture radar earthquake source models: 1. Comparisons with seismic catalogs, J. Geophys. Res. 116, no. B8, doi: 10.1029/2010JB008131.

Zhan, Z., D. Helmberger, M. Simons, H. Kanamori, W. Wu, N. Cubas, Z. Duputel, R. Chu, V. Tsai, J. Avouac, K. W. Hudnut, S. Ni, E. Hetland, and F. Culaciati (2012). Anomalously steep dips of earthquakes in the 2011 Tohoku-Oki source region and possible explanations, Earth Planet. Sci. Lett. 353, 121-133.

Zhao, L. S., and D. V. Helmberger (1994). Source estimation from broadband regional seismograms, Bull. Seismol. Soc. Am. 84, no. 1, 91.

Zhu, L., and D. V. Helmberger (1996). Advancement in source estimation techniques using broadband regional seismograms, Bull. Seismol. Soc. Am. 86, no. 5, 1634.

Zhu, L., and L. A. Rivera (2002). A note on the dynamic and static displacements from a point source in multilayered media, Geophys. J. Int. 148, no. 3, 619-627.

Zwick, P., R. McCaffrey, and G. Abers (1994). MT5 program, in Bibliographic References and BSSA Database (August, 1994), Vol. 4, IASPEI Software Library.

Weiwen Chen Zhe Jia

National Geophysical Observatory at Mengcheng School of Earth and Space Sciences University of Science and Technology of China Hefei 230026, China Sidao Ni
State Key Laboratory of Geodesy and Earth's Dynamics
Institute of Geodesy and Geophysics
Chinese Academy of Sciences
Wuban 430077, China
sdni@whigg.ac.cn

Hiroo Kanamori Shengii Wei Seismological Laboratory Division of Geological and Planetary Sciences California Institute of Technology Pasadena, California 91125 U.S.A.

Lupei Zhu School of Earth and Atmosphere Sciences Saint Louis University Saint Louis, Missouri 63103 U.S.A.

Published Online 28 January 2015 